\title{
The prevalence of clinical diabetic polyneuropathy in Spain: a study in primary care and hospital clinic groups
}

\author{
J. Cabezas-Cerrato for the Neuropathy Spanish Study Group of the Spanish Diabetes Society (SDS) \\ Department of Endocrinology and Nutrition, C.H. U.S., Santiago de Compostela, Spain
}

\begin{abstract}
Summary A multiregional cross-sectional study of clinical diabetic polyneuropathy (DPN) was carried out among Spanish diabetes patients using a standard system for scoring symptoms and signs of polyneuropathy. The main patient sample comprised 2644 patients $(54.7 \%$ women) aged $15-74$ years (mean $57.2 \pm 0.3$ years), $86.9 \%$ of whom had Type II (noninsulin-dependent) diabetes mellitus and $29.4 \%$ were attending hospital clinics. Mean duration of diabetes since diagnosis was $10.2 \pm 0.2$ years. The prevalence of DPN was $22.7 \%$ (95\% confidence interval $21.2-24.3 \%$ ) in the whole sample, $12.9 \%$ (9.4-16.5\%) among patients with Type I (insulin-dependent) diabetes mellitus and $24.1 \%$ (22.4-25.9\%) among patients with Type II diabetes; there was no significant difference in prevalence between men and women. Prevalence increased with age (from $<5 \%$ in the 15 - to 19 -year-old age group to $29.5 \%$ in the 70- to 74-year-old group) and with duration of diabetes since diagnosis (from $14.2 \%$ among those with duration $<5$ years to $44.2 \%$ among those with duration $>30$ years). In a supplementary sample of
\end{abstract}

161 diabetic patients aged 75 to 79 years (excluded from the main sample to prevent confusion between diabetes-induced and ageing-induced neuropathies), prevalence was $37.8 \%$. Ninety-three patients $(3.3 \%)$ had or had had foot ulcers and 21 of these $93(0.7 \%)$ had undergone amputation; $90.8 \%$ of ulcerated patients had Type II diabetes, and $54 \%$ had DPN (in most cases with loss of perception of vibration), as against a prevalence of DPN of $19.9 \%$ among patients without ulcers. We conclude that nearly a quarter of Spanish diabetic patients have DPN; that over $90 \%$ of DPN patients have Type II diabetes; that the prevalence of DPN increases with age and with the duration of the disease, and that the risk of foot ulcers among DPN patients is about three times the risk among diabetic patients without DPN. We accordingly emphasize the responsibility of primary care physicians to try to prevent diabetic foot lesions by early diagnosis of DPN. [Diabetologia (1998) 41:1263-1269]

Keywords Diabetes, polyneuropathy, epidemiology, Type I, Type II, foot ulcers
In Spain, as in other industrialised nations, diabetes, with an estimated prevalence of $3.7 \%$ [1, 2], constitutes a major cause of suffering and a major burden on the health system. In both cases, it is the specific

Received: 10 March 1998 and in final revised form: 8 June 1998

Corresponding author: Professor José Cabezas-Cerrato, Department of Endocrinology and Nutrition, C.H.U.S.: H. General de Galicia, c/Galeras, s/n, 15705 Santiago de Compostela, Spain

Abbreviations: DPN, Diabetic polyneuropathy; NDS, neuropathy disability score; NSS, neuropathy symptom score complications of diabetes that are chiefly to blame. As an aid to managing health resources, we have therefore studied the prevalence of diabetic polyneuropathy among Spanish diabetic patients.

Previous studies of the prevalence of diabetic polyneuropathy [3-14] had widely differing results. This was attributable to differences in the kind of patient sample (most samples were recruited in specialised centres); to whether or not the neurological effects of ageing were taken into account; and to study or diagnostic methods and criteria or both (studies differed as to whether they included neurophysiological tests in the diagnostic protocol; target- 
Table 1. Sample characteristics and prevalence of polyneuropathy

\begin{tabular}{|c|c|c|c|c|c|}
\hline Sample & $n$ & $\%$ & Age (years) & $\begin{array}{l}\text { Duration of diabetes } \\
\text { (years) }\end{array}$ & prevalence $\%$ \\
\hline Whole sample & 2644 & 100 & $57.2 \pm 0.3$ & $10.2 \pm 0.2$ & $22.7(21.2-24.3)$ \\
\hline $\begin{array}{l}\text { Diabetes } \\
\text { Type I } \\
\text { Type II }\end{array}$ & $\begin{array}{r}348 \\
2296\end{array}$ & $\begin{array}{l}13.2 \\
86.9\end{array}$ & $\begin{array}{l}30.5 \pm 0.6^{\mathrm{a}} \\
61.3 \pm 0.2\end{array}$ & $\begin{array}{c}13.8 \pm 0.5^{\mathrm{a}} \\
9.7 \pm 0.2\end{array}$ & $\begin{array}{l}12.9(9.4-16.5)^{\mathrm{a}} \\
24.1(22.4-25.9)\end{array}$ \\
\hline $\begin{array}{l}\text { Sex } \\
\text { Men } \\
\text { Women }\end{array}$ & $\begin{array}{l}1197 \\
1447\end{array}$ & $\begin{array}{l}45.3 \\
54.7\end{array}$ & $\begin{array}{l}56.3 \pm 0.4^{\mathrm{b}} \\
57.9 \pm 0.4\end{array}$ & $\begin{array}{r}9.8 \pm 0.2^{\mathrm{b}} \\
10.6 \pm 0.2\end{array}$ & $\begin{array}{l}22.0(19.6-24.3)^{\mathrm{c}} \\
23.2(21.0-25.4)\end{array}$ \\
\hline $\begin{array}{l}\text { Origin } \\
\text { Hospital } \\
\text { Primary health care centre }\end{array}$ & $\begin{array}{r}778 \\
1866\end{array}$ & $\begin{array}{l}29.4 \\
70.6\end{array}$ & $\begin{array}{l}49.3 \pm 0.6^{\mathrm{a}} \\
60.5 \pm 0.3\end{array}$ & $\begin{array}{c}12.4 \pm 0.3^{\mathrm{a}} \\
9.3 \pm 0.2\end{array}$ & $\begin{array}{l}26.7(23.6-29.8)^{\mathrm{b}} \\
21.0(19.1-22.8)\end{array}$ \\
\hline
\end{tabular}

Values of age and duration are mean \pm SEM. For prevalence the $95 \%$ confidence interval is given in parenthesis. Differences of values between rows are as follows: ${ }^{\mathrm{a}} p<0.001,{ }^{\mathrm{b}} p<0.05,{ }^{\mathrm{c}} p$ : NS

ed somatic or autonomic neuropathy; or distinguished between clinical diabetic polyneuropathy and mononeuropathy, multineuropathy, polyneuropathy of non-diabetic origin and subclinical forms of diabetic polyneuropathy). In our study, the prevalence of clinical diabetic polyneuropathy (DPN) was defined as ,symmetrical sensorymotor polyneuropathy predominantly affecting the distal aspects of the lower limbs and due to diabetes mellitus. Sensory symptoms and deficits, a variable degree of autonomic dysfunction, and infrequent muscle weakness are characteristics" [15]. We determined such prevalence among diabetic patients attending both hospital and primary care clinics, in relation to patient age and sex, diabetes type and the duration of diabetes since diagnosis.

\section{Subjects, materials and methods}

Subjects. A main sample consisting of 2644 diabetic patients aged 15 to 74 years was studied; younger patients were excluded to avoid comprehension difficulties and older patients to avoid interference from the effects of ageing on the nervous system. In addition, 161 diabetic patients aged 75 to 79 years were examined. Neither sample contained patients who drank more than 15 units of alcohol a week or patients judged to have non-diabetic polyneuropathy using the criteria specified below. Both samples were proportionally distributed among the Spanish Autonomous Communities. In order to sample the whole diabetic population rather than just those patients attending hospital clinics, $70-75 \%$ of the subsample corresponding to each Autonomous Community was taken from primary care centres (this figure is an estimate that roughly corresponds to the percentage of diabetic patients attending primary care centres). Within each centre, every third or fourth patient was included in the sample until the quota for the centre was completed. Data were collected between April 1996 and September 1997. The chief characteristics of the sample are listed in Table 1.

Methods. A standard data sheet (with slight modifications) was used to record the symptoms and signs used for neuropathy symptom score (NSS) and neuropathy disability score (NDS)
[10]. For the NDS, the ankle reflex and perceptions of pinprick, cold and vibration were evaluated bilaterally. Pinprick perception was evaluated at the root of the great toe nail, cold perception by placing a cold tuning fork on the back of the foot and vibration perception by placing the vibrating $128 \mathrm{~Hz}$ tuning fork against the apex of the great toe. In patients aged over 64 years, percussion of the sole was used to elicit the ankle reflex if the usual stimuli had proved unsuccessful. On either side, the ankle reflex scored 0 if present and normal and 2 if absent, and the three perceptions scored 0 if present and normal and 1 if absent, reduced or uncertain, although following previous indications [16]. All participating physicians attended at least one training session before collecting data.

The criteria for diagnosis of DPN were an NDS score of at least 6, regardless of NSS score, or an NDS score of 3-5 in conjunction with an NSS score of at least 5 . These criteria were fixed at the start of the study by the study coordinator but were not disclosed to other participants until the study had been concluded.

Statistical analysis. Patient subgroups were compared for prevalence of DPN by means of chi-square tests and the MannWhitney U test was used to estimate the significance of differences in the means of other variables between the groups. Pearson correlations between age or duration since diagnosis and prevalence in age/duration groups were calculated. Multivariate logistic regression analysis was carried out to identify risk factors associated with DPN. All statistical analyses were done using SPSS for Windows.

\section{Results}

Table 1 shows the general characteristics of the sample and the prevalence of DPN in the whole sample of 15- to 74-year-old subjects and in various subsets. Overall prevalence in this main sample was $22.7 \%$. There was no difference in prevalence between the sexes, but there was a great difference between insulin-dependent and non-insulin-dependent diabetic patients, $12.9 \%$ as against $24.1 \%(p<0.001)$.

In both types of diabetes prevalence rose continuously with age with a correlation of 0.96 between prevalence and age $(p<0.001)$. Above age 74 years, the prevalence of DPN rose sharply, with a value of 

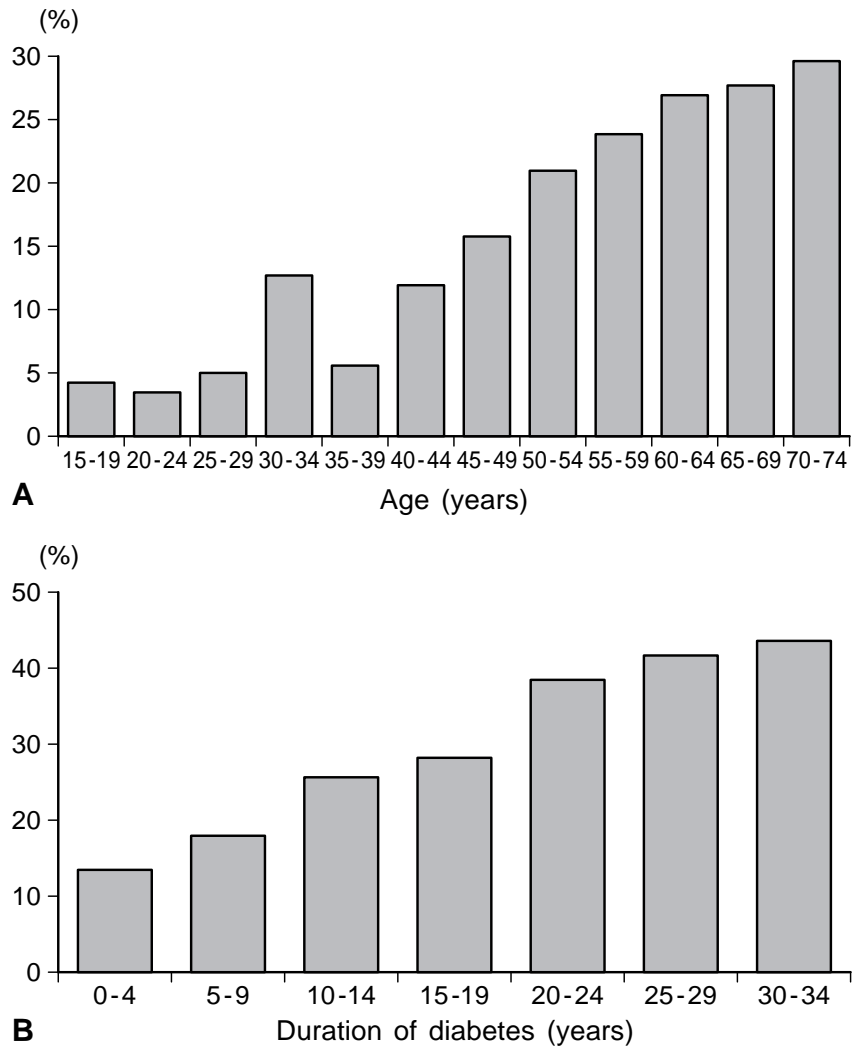

Fig. 1A, B. Prevalence of clincical diabetic neuropathy among Spanish diabetic patients, by patient age (A) and duration of diabetes (B)

$37.8 \%$ in the sample of 74- to 79-year-olds as against $29.5 \%$ in the 70- to 74-year group (Fig. 1, 2).

In both groups, prevalence increased fairly steadily with the duration of diabetes since diagnosis. Overall, there was a correlation of 0.98 between prevalence and duration of diabetes since diagnosis $(p<0.001)$. The duration of Type II diabetes prior to diagnosis was estimated as 12.5 years by extrapolating the prevalence-duration regression line for this group back to zero prevalence (Fig. 3).

Among patients attending primary care centres the prevalence of DPN was less than among hospital clinic patients, $21.0 \%$ as against $26.7 \%(p<0.05)$. There was no significant correlation between prevalence and smoking (grouping patients as non-smokers, or smokers of $<10,10-20$ and $>20$ cigarettes a day) or alcohol consumption (alcohol consumption was limited by the criteria for inclusion in the study but within this limit we looked for differences in prevalence among non-drinkers, occasional drinkers or habitual drinkers).

Multiple logistic regression analysis of the dependence of DPN prevalence on sex, age, duration of diabetes and origin of patients was done for the Type I and Type II subsamples separately because of the differences in age and duration of diabetes between both groups (Table 2). In the Type I group only dura-
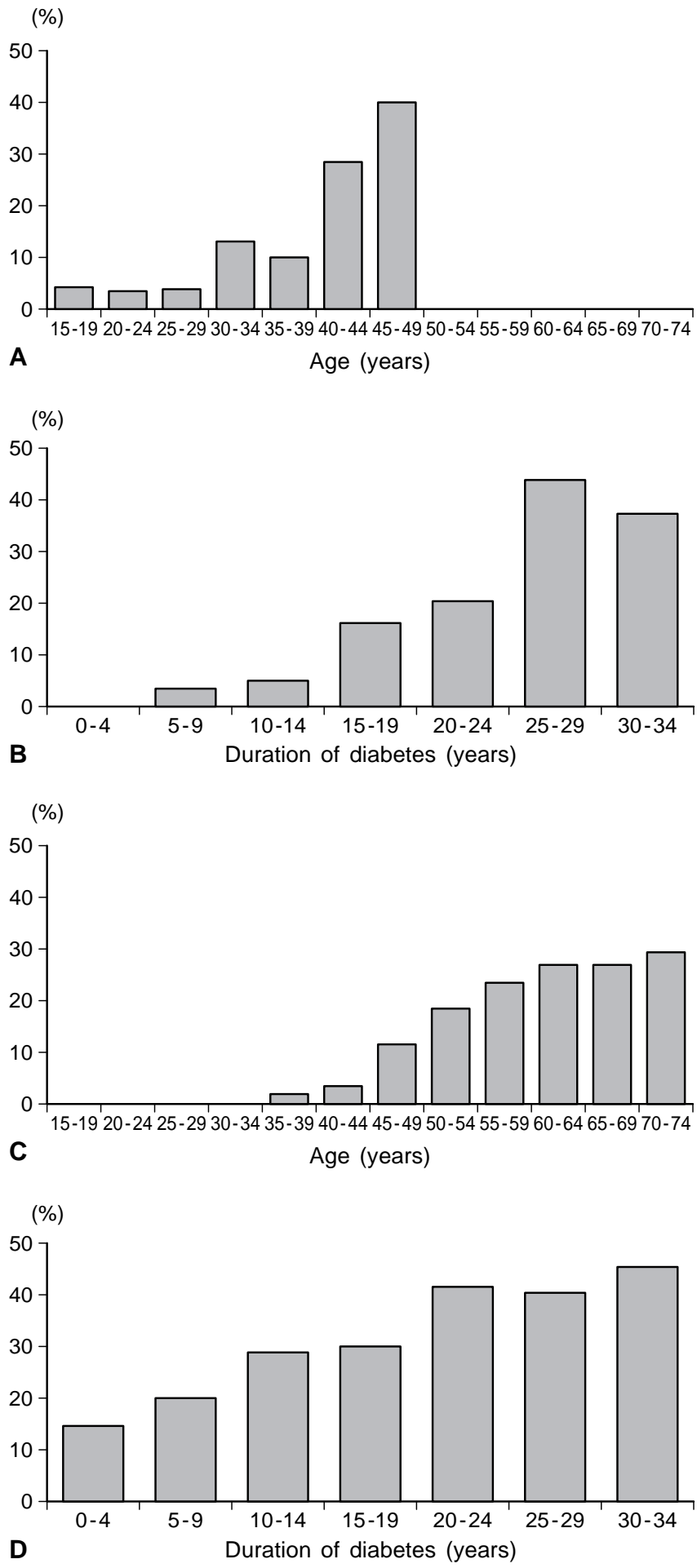

Fig. 2. Prevalence of clinical diabetic neuropathy among spanish diabetic patients of Type I (A and $\mathbf{B})$ and in Type II (C and D) increases with age (A and $\mathbf{C})$ and duration of diabetes since diagnosis (B and $\mathbf{D})$

tion of diabetes showed an association with DPN prevalence $(p<0.05)$ but in the Type II group both age and duration of diabetes were associated with DPN prevalence $(p<0.001)$. Another model including the origin of patients as a variable showed an 


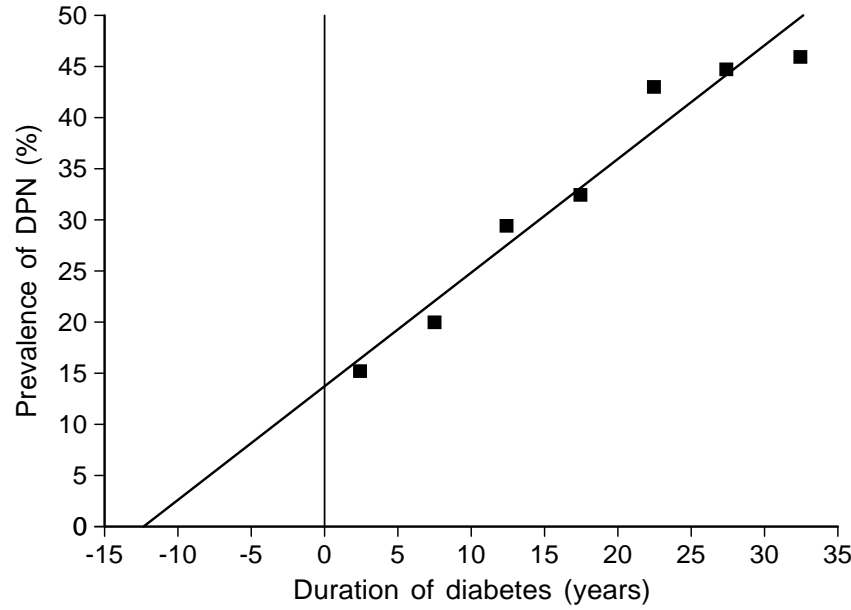

Fig.3. Linear regression of the prevalence of clinical diabetic polyneuropathy on duration of diabetes since diagnosis. Extrapolation to zero prevalence estimates the onset of polyneuropathy as 12.5 years prior to diagnosis of diabetes

association only in the Type II group; age, duration of diabetes and origin of patients was associated with DPN prevalence $(p<0.001)$. Sex was not significantly associated with prevalence in any model or group.

In the pooled 15- to 74-year-old and 75- to 79-yearold samples, 93 patients $(3.3 \%)$ had or had had foot ulcers and 21 of these $93(0.7 \%$ of the total $)$ had undergone amputation; $90.8 \%$ of the patients with ulcers had Type II diabetes. Table 3 shows the associa- tion between ulceration and the absence of ankle reflex or vibration perception in the 2805-member group and its Type I and Type II diabetic subgroups.

\section{Discussion}

The results show an overall prevalence of DPN of $22.7 \%$ in the 15 - to 74-year-old sample. The discrepancy with respect to the $28.5 \%$ for the United Kingdom [10] is doubtless due to the restriction to patients attending hospital clinics, whereas $70.6 \%$ of our patients attended primary care centres: patients with complications tend to be monitored at hospital clinics rather than primary care centres. The prevalence of DPN among hospital patients in our study, $26.7 \%$, is similar to that reported by the British study.

Our results agree with those of other studies that have examined Type I diabetic patients [6, 13, 17-20], Type II diabetic patients $[4,5,7,8,11,12]$ or both Type I and Type II patients [3, 9, 10, 14] in finding higher prevalence of DPN in Type II diabetes. Our $35.4 \%$ prevalence for Type II diabetic hospital patients is similar to the $32.1 \%$ for the British study [10]. That for Type I diabetic hospital patients there is a difference from that study $(13.2 \%$ as against $22.7 \% ; p<0.001)$ is probably due to the median age of our Type I diabetic hospital patients having been 28 years as against 45 years in the British study (Type II diabetic hospital patients had a median age of 63 years in both studies).

Table 2. Results of logistic regression analysis of DPN status on: age, diabetes duration, sex and origin of patients. Analysis is performed separately for Type I and Type II. In parenthesis are given the $95 \%$ confidence intervals for the odds ratios

\begin{tabular}{|c|c|c|c|c|}
\hline Variable & Parameter estimate & Standard error & $p$-value & Odds ratio \\
\hline \multicolumn{5}{|l|}{ Type I } \\
\hline Age & 0.0434 & 0.0257 & NS & $1.04(0.99-1.10)$ \\
\hline Duration & 0.0880 & 0.0287 & $<0.05$ & $1.09(1.03-1.15)$ \\
\hline Sex & -0.3621 & 0.3662 & NS & $0.99(0.34-1.43)$ \\
\hline Origin & 0.5651 & 0.4466 & NS & $1.76(0.73-4.22)$ \\
\hline Constant & -4.5561 & 0.6537 & & \\
\hline \multicolumn{5}{|l|}{ Type II } \\
\hline Age & 0.0380 & 0.0063 & $<0.001$ & $1.04(1.03-1.05)$ \\
\hline Duration & 0.0469 & 0.0062 & $<0.001$ & $1.05(1.03-1.07)$ \\
\hline Sex & -0.0145 & 0.1009 & NS & $0.99(0.83-1.24)$ \\
\hline Origin & 0.6293 & 0.1140 & $<0.001$ & $1.88(1.50-2.35)$ \\
\hline Constant & -4.1692 & 0.4000 & & \\
\hline
\end{tabular}

Model: $\log (\mathrm{P} / 1-\mathrm{P})=$ constant $+\beta_{1}$ age $+\beta_{2}$ duration $+\beta_{3}$ sex $+\beta_{4}$ origin, where $\mathrm{P}$ is the probability of having neuropathy. Sex code: male $=0$, female $=1$. Origin code: hospital: 1 , primary care centre: 0

Table 3. Prevalence of neurological signs in groups defined by presence of foot ulcer and diabetes type

\begin{tabular}{llllllll}
\hline & \multicolumn{2}{l}{ Absent ankle reflex } & & \multicolumn{3}{l}{ Absent vibratory perception } \\
\cline { 2 - 3 } & Overall & Type I & Type II & & Overall & Type I & Type II \\
\hline Foot ulcer & $44.8 \%$ & $37.5 \%$ & $45.6 \%$ & & $47.1 \%$ & $37.5 \%$ & $18.1 \%$ \\
No foot ulcer & $26.0 \%$ & $19.1 \%$ & $27.1 \%$ & & $18.6 \%$ & $10.0 \%$ & $19.9 \%$ \\
\hline
\end{tabular}

Differences of prevalence of absence of ankle reflex and vibratory perception between patients with and patients without foot ulcers are significant on the whole sample and in the Type II group $(p<0.001)$ 
To prevent the sample from being contaminated by patients with mononeuropathy, multineuropathy or non-diabetic polyneuropathy, which has an estimated prevalence of 6-10\% [21], some rigorous exclusion criteria were used including alcohol intake more than 15 units a week. This resulted in an homogeneous sample in which there were no differences in DPN prevalence between non-drinkers, occasional drinkers or habitual drinkers.

The diagnostic procedures used in studies of DPN have included assessment of symptoms alone [8] or signs alone [22], quantitative sensory tests [23], and various combinations of these methods: symptoms and signs $[6,9,10]$; signs and electrophysiological tests [14]; symptoms, signs and electrophysiological test $[11,13]$; and symptoms, signs, electrophysiological tests and quantitative sensory tests [24, 25]. This variety of methods has contributed to discrepancies among the results. To enhance the meaningfulness of direct comparison of our results with those of the British study [10] which is the largest European study of the prevalence of DPN among both Type I and Type II patients, we used (with two exceptions) the same diagnostic methods and criteria as in that study.

The two points in which our method differed were that we excluded patients older than 74 years from the main study and, for patients older than 64 years, percussion of the sole was used to elicit the ankle reflex if the usual, less powerful, stimuli had proved unsuccessful. Both measures were adopted to prevent contamination of the sample by patients with polyneuropathy due to normal ageing rather than to the diabetes. The prevalence of signs and symptoms of polyneuropathy (paraesthesia, numbness, and reduction or absence of ankle reflex, positional awareness and perception of vibration, pinprick or pressure or both), though much less among normal subjects than among diabetic patients of the same age and sex, has been found not to be negligible among normal subjects aged more than 70 years [26]. Similarly, symptoms and signs compatible with a diagnosis of polyneuropathy have been found in $2.9 \%$ of 480 non-diabetic subjects [9], and in $2.1 \%$ of control subjects [11]. Our results suggest that the two measures taken to exclude ageing-induced polyneuropathy were largely successful, since prevalence rose quite smoothly with age to $29.5 \%$ in the 70 - to 74 -year-old age group but then jumped sharply to $37.8 \%$ among 75- to 79-year-olds. In the British study, prevalence was about $44 \%$ at age 74 years and $55 \%$ at age 85 years [10].

Like that study, we found no difference in DPN rate between the sexes. This contrasts with the results of other studies [3,8], which found greater prevalence among men than among women. Neither of these studies is, however, properly comparable with ours or the British study: the first did not use symptoms for diagnosis and did not distinguish between poly- neuropathy and mononeuropathy or multineuropathy; and the second only comprised Type II diabetic patients.

Like autonomic neuropathy [27], DPN is more prevalent among Type II than among Type I diabetic patients [10, this study]. This could be due to the period of occult hyperglycaemia preceding diagnosis being longer in Type II than in Type I diabetes but it has also been suggested that Type II, but not Type I, diabetes involves the action of neurotoxic agents other than glucose [28]. This hypothesis has been supported by pointing to the contrast between the rate of increase in prevalence among Type I diabetic patients estimated in a longitudinal study as $2.5 \%$ per year of duration [20] and the rate we estimated from reported data for Type II diabetic patients [11] as $3.6 \%$ per year of duration. It is possible, however, that this data was an overestimate: arrived at by comparing the prevalence of about $8 \%$ in newly diagnosed Type II diabetic patients found in that [11] and other studies $[3,7]$ with the percentage obtained from the 10-year follow-up in that study. It implies on average DPN develops for about 2 years before diagnosis, a much shorter time than the 12.5 years we found in this study or the 4-7 years estimated in a study of retinopathy among Australian and USA Type II diabetic patients [29]. In view of these longer estimates of pre-diagnosis duration of polyneuropathy, and of the new criteria proposed for diagnosis of diabetes [30], we believe it likely that the only causes of the greater prevalence among Type II diabetic patients are the duration of the disease and the older age of Type II diabetic patients, which probably acts via effects on microcirculation and the ensuing ischaemia [31].

For a variety of reasons, diabetic patients with DPN are liable to develop foot ulcers or require amputation [32-35]. In this study, 93 patients $(3.3 \%$ of the whole sample) had or had had foot ulcers and 21 of these $93(0.7 \%$ of the total $)$ had undergone amputation; $91.4 \%$ of the patients with ulcers had Type II diabetes. That DPN was diagnosed in $57.0 \%$ of the 93 (on the basis of signs including zero perception of vibrations in 45 patients), as against only $19.9 \%$ of DPN patients without ulcers, confirms that DPN in general, and reduced perception of vibration in particular [32], are major risk factors for neuropathic foot ulcers in diabetes.

In conclusion, in this study of a total of 2805 diabetic patients recruited from primary health care centres and hospital clinics in 14 of the 17 Spanish Autonomous Communities we found that nearly a quarter had DPN (over $90 \%$ of them were Type II diabetic patients) and that prevalence increased with age and the duration of the disease. Although the prevalence of DPN was naturally greater among hospital patients than among those attending primary centres, the number of cases detected in the second was 
almost twice the number detected at hospitals. Since patients in whom DPN had been diagnosed were about three times more likely to develop foot ulcers or require amputation than patients without DPN, the major role that primary care physicians play in the prevention of diabetic foot lesions becomes obvious.

Acknowledgements. NEURODIABES is one of the Spanish Diabetes Society Study Groups, all of their members thank its institutional support. This study in its material and logistic aspects was sponsored by Novo Nordisk Pharma.

\section{The Spanish Neuropathy Study Group (NEURODIABES)}

Steering committee coordinators: José Cabezas-Cerrato (general coordinator), M. Aguilar Diosdado, J. Barbería Layana, P. Benito López, R. Ma Burgo López, H. de la Calle Blasco, A. L. Calle Pascual, R. Carmena Rodríguez, F. J. Díaz Cadórniga, E. Esmatjes Mompo, E. Faure Nogueras, J.L. Herrera Pombo, J. A. Lobón Hernández, J. López López, J. A. Mato Mato, M. Muñoz, Ma del Pino Navarro, L. F. Pallardo Sánchez, J. M ${ }^{\text {a }}$ Pou Torelló, W. Ricart Engel, R. Simó Canonge, F. J. Tébar Massó, J. A. Vázquez García, O. Vidal Vázquez, J. Zurro Hernández.

General practitioners and endocrinologists: M. Abad Vila, M. Abuín Rodríguez, Sh. Adrid, A. del Álamo Alonso, R. Alarcón, J. Alcántara Nicolás, A. Alonso Marquíegui, J. Álvarez, K. Álvarez, C. Álvarez Escola, P. Álvarez Vega, F. J. Ampudia Blasco, M. Bacarizas, $\mathrm{M}^{\mathrm{a}}$ D. Ballesteros, P. Bárez Hernández, C. Becerro, F. Benito Romaguera, J. Bertola, J. J. Blanquer, Ma A. Bueno Gascón, M. Bueno, L. Cacho, J.M. Caeiro Castelao, J. R. Calle, R. Calle Custodio, B. Calzadillas, M. Caro, G. Castaño Fernández, M. Catalá Bauset, V. Castro Ocampo, D. Corpas, F. Cortés Traver, E. Cortina, A. Costa Alcaraz, A. Díaz, G. Díaz, C. Díez de Greñu, F. Escobar-Jiménez, C. Fernández, J.M. Fernández-Real, C. Fernández Barredo, J. M ${ }^{\mathrm{a}}$ Fernández-Cañadas, J. M ${ }^{\mathrm{a}}$ Fernández Rodríguez, $\mathrm{M}^{\mathrm{a}} \mathrm{J}$. Fernández Silva, L. Flores, J. Forcada Lozano, L. Fraile, A. Frechina Ortiz, J. Fuentes, L. Fuentes, E. Galindo Alonso, M A A. Gálvez, D. García, P. García, J. J. García Gallego, J. M. García López, L. García Ortiz, J. A. García del Río, G. García Tell, C. Gerpe Caamaño, A. Gippini Pérez, R. Girona, I. Goicolea, Ma Gómez Mosquera, M. Gómez Marcos, C. González, J. González, A.González Álvarez, J.M. González-Clemente, M $^{\mathrm{a}}$ J. Goñi Iriarte, R. Gulín García, T. Gutierrez Renedo, M. Gutierrez Salas, M. Hernández, J. A. Iglesias Valiente, I. Jaén, D. Jimena, L. Jimena, B. Lahoz Rallo, A. Larnia, E. Lázaro Merino, J. López, Ma E. López Docasar, F. Malo García, R. $\mathrm{M}^{\mathrm{a}}$ Mareque Alonso, P. Marín Lluch, N. Mariño Rodríguez, J. L. Martín Manzano, P. Martín Vaquero, C. Martínez Faedo, M. Martínez Pillado, J. Martínez Valls, M D. Mini Castro, S. Miralles, J. M. Miralles García, A. Molina Blanco, I. Morán, P. Moreno González, E. Moreno Rodríguez, Ma D. Muñoz, V. Muñoz, P. Navalón, J. M. Navarrete Villalta, C. Olcina, R. Orueta, J. A. Paniagua, M. Paz de Miguel, P. J. Pazos, P. Pérez de Aguilar, B. Pérez Roibas, A. Picó, F. Piñeiro, M.L. Planells Mateu, F. Plaza Verdesoto, A. Priego Serrano, L. Prieto Robisco, J. Prieto Santiago, A. Proupín Vázquez, J. M. Puerta Vázquez, M. Quesada Charneco, M. A. Rabanal, J.L. Ramil Hermida, Ma J. Redondo, D. Redondo Herrero, $M^{\mathrm{a}}$ J. Roche Asensio, J. Rodríguez, T. Rodríguez Fernández, Ma T. Rodríguez Vega, C. Romero, M. Rondán Fernández, B. Ruano, I.
Sáez del Castillo, A. I. Sala López, C. Salvador Aguiar, C. San Juán Villafranca, M ${ }^{a}$ I. Sánchez Herrero, C. Sánchez Juán, B. Sánchez Sancha, J. Sanfélix Genovés, J. Santamaría, J. Santo-

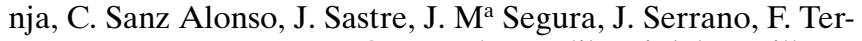
cero Mora, $\mathrm{M}^{\mathrm{a}} \mathrm{T}$. Torres, C. Tronch, J. Ulibarri del Portillo, P. Valencia, I. Vázquez de Prada, R. Veras Castro, I. Vicedo, L. Vicéns, A. Vicente, R. Vigara, R. Vilariño Méndez, A. Villanueva, A. L. Villarias, C. Wals Zurita, I. Zurro Muñoz.

Data analysis: C. Rega

\section{References}

1. Hart WM, Espinosa C, Rovira J (1997) Cost of known diabetes mellitus in Spain. Med Clin (Barc) 109: 289-293

2. Hart WM, Espinosa C, Rovira J (1997) A simulation model of the cost of the incidence of IDDM in Spain. Diabetologia 40: 311-318

3. Pirart, J (1979) Diabetes mellitus and its degenerative complications: a prospective study of 44000 patients observed between 1947 and 1973. Diabetes Care 1: 168-188

4. Palumbo PJ, Elveback LR, Whisnant PJ (1978) Neurologic complications of diabetes mellitus: transient ischemic attack, stroke and peripheral neuropathy. Adv Neurol 19: 593-601

5. Knuiman MW, Welborn TA, McCann VJ, Stanton KG, Constable IJ (1986) Prevalence of diabetic complications in relation to risk factors. Diabetes 35: 1332-1339

6. Boulton AJM, Knight G, Drury J, Ward JD (1985) The prevalence of symptomatic diabetic neuropathy in an insulin-treated population. Diabetes Care 8: 125-128

7. Lehtinen JM, Uisutupa M, Siitonen O, Pyörälä K (1989) Prevalence of neuropathy in newly diagnosed NIDDM and non diabetic control subjects. Diabetes 38: 1307-1313

8. Franklin, GM, Kahn LB, Bacter J, Marshall JA, Hamman RF (1990) Sensory neuropathy in non-insulin dependent diabetes mellitus. The San Luis Valley study. Am J Epidemiol 131: 633-643

9. Walters DP, Gatling W, Mullee MA, Hill RD (1992) The prevalence of diabetic distal sensory neuropathy in an English Community. Diabet Med 9: 349-353

10. Young MJ, Boulton AJM, MacLeod AF, Williams DRR, Uusitupa Sonksen PH (1993) A multicenter study of the prevalence of diabetic peripheral neuropathy in the United Kingdom hospital clinic population. Diabetologia 36: 150-154

11. Partanen J, Niskanen L, Lehtinen J, Mervaala E, Siitonen OM (1995) Natural history of peripheral neuropathy in patients with non-insulin dependent diabetes mellitus. N Eng J Med 333: 89-94

12. Sands ML, Shetterly MS, Franklin GM, Hamman RF (1997) Incidence of distal symmetric (sensory) neuropathy in NIDDM. Diabetes Care 20: 322-329

13. Tesfaye S, Stevens LK, Stephenson JM et al. and The EURODIAB IDDM study group (1996) Prevalence of diabetic peripheral neuropathy and its relation to glycaemic control and potential risk factors: the EURODIAB IDDM Complications Study. Diabetologia 39: 1377-1384

14. Fedele D, Comi G, Coscelli C et al. (1997) A multicenter study on the prevalence of diabetic neuropathy in Italy. Diabetes Care 20: 836-843

15. Peripheral Nerve Society (1995) Diabetic polyneuropathy in controlled clinical trials: consensus report of the peripheral nerve society. Ann Neurol 38: 478-482 
16. Dyck PJ, Litchy WJ, Lehman KA, Hokanson JL, Low PA, O'Brien PC (1995) Variables influencing neuropathic endpoints: The Rochester Diabetic Neuropathy Study of Healthy Subjects. Neurology 45: 1115-1121

17. Ziegler D, Cicmir Y, Wiefels K, Berger H, Gries FA (1987) Peripheral and autonomic nerve function in long-term insulin-dependent diabetes. Diabetes Res 4: 9-14

18. Ziegler D, Mayer P, Gries FA (1988) Evaluation of thermal, pain, and vibration sensation thresholds in newly diagnosed type 1 diabetic patients. J Neurol Neurosurg Psychiatry 51: 1420-1424

19. Ziegler D, Mayer P, Wiefels K, Gries FA (1988) Assessment of small and large fibre function in long-term type I (insulin-dependent) diabetic patients with and without painful neuropathy. Pain 34: 1-10

20. Ziegler D, Mayer P, Mühlen H, Gries FA (1991) The natural history of somatosensory and autonomic nerve dysfunction in relation to glycaemic control during the first 5 years after diagnosis of Type I (insulin-dependent) diabetes mellitus. Diabetologia 34: 822-829

21. Dyck PJ (1997) The near-future direction of research and medical core of human diabetic neuropathies. Neuroscience Res Communications 21: 5-12

22. The Diabetes Control and Complications Trial (DCCT) (1993) N Engl J Med 329: 683-689

23. Masson EA, Hunt, Gem JM, Boulton AJM (1989) A novel approach to the diagnosis and assessment of symptomatic diabetic neuropathy. Pain 38: 25-28

24. Feldman EL, Stevens MJ, Thomas PK, Brown MB, Canal N, Greene DA (1994) A practical two-step quantitative clinical and electrophysiological assessment for the diagnosis and staging of diabetic neuropathy. Diabetes Care 11:1281-1289

25. Dyck, PJ, Kratz KM, Lehman KA et al. (1991) The Rochester Diabetic Neuropathy Study: design, criteria for types of neuropathy, selection bias, and reproductibility of neuropathic tests. Neurology 41: 799-807

26. Mayne N (1965) Neuropathy in the diabetic and non-diabetic population. Lancet ii:1313-1316

27. Ziegler D, Gries FA, Spüller M,Lessmann F (1992) Diabetic cardiovascular autonomic neuropathy Multicentre Study Group. The epidemiology of diabetic neuropathy. J Diabetes Complications 6: 25-33

28. Ziegler D, Mühlen H, Gries FA (1992) Neurophysiological tests in Type 1 (insulin-dependent) and Type II (non-insulin-dependent) diabetic patients with subclinical and symptomatic neuropathy. Diabetologia 35: 1099-1100

29. Harris MI, Klein R, Welborn TA, Knuiman MW (1992) Onset of NIDDM occurs at least 4-7 yr before clinical diagnosis. Diabetes Care 15: 815-819

30. American Diabetes Association: Report of the expert committee on the diagnosis and classification of diabetes mellitus (1997) Diabetes Care 20: 1183-1197

31. Dyck PJ, Giannini C (1996) Pathologic alterations in the diabetic neuropathies of human: A review. J Neuropathol Exp Neurol 55: 1181-1193

32. Boulton AJM, Kubrusly D, Bowker JH et al. (1986) Impaired vibratory perception and diabetic foot ulceration. Diabet Med 3: 335-337

33. Mueller MJ, Minor SD, Sahrmann ShA, Schaaf JA, Strube MJ (1994) Differences in the gait characteristics of patients with diabetes and peripheral neuropathy compared with age-matched controls. Phys Ther 74: 299-308

34. Katoulis EC, Ebdon-Parry M, Lanshammar H, Vileikyte L, Kulkarni J, Boulton AJM (1997) Gait abnormalities in diabetic neuropathy. Diabetes Care 20: 1904-1907

35. Katoulis EC, Ebdon-Parry M, Hollis S et al. (1997) Postural instability in diabetic neuropathic patients at risk of foot ulceration. Diabet Med 14: 296-300 